\title{
LEVANTAMENTO QUANTITATIVO DE RESÍDUOS SÓLIDOS, ESTUDO DE CASO NO RESTAURANTE UNIVERSITÁRIO DA UFRA, CAMPUS BELÉM.
}

João André Lima Pereira - andre_alfafa@ hotmail.com

Universidade Federal Rural da Amazônia

Brenda Ribeiro Chagas - brendachagas1@gmail.com

Universidade Federal Rural da Amazônia

Eva Vanone da Silva Cardoso Pelerano - evacpelerano@gmail.com

Universidade Federal Rural da Amazônia

Fernando Bosco de Sousa Melo - fernandobosco31@ gmail.com

Universidade Federal Rural da Amazônia

Maria José Tavares de Oliveira - tavaresjo@ hotmail.com

Universidade Federal Rural da Amazônia

Thaciane Christine Coelho da Silva - thacianesilva@outlook.com.br

Universidade Federal Rural da Amazônia 


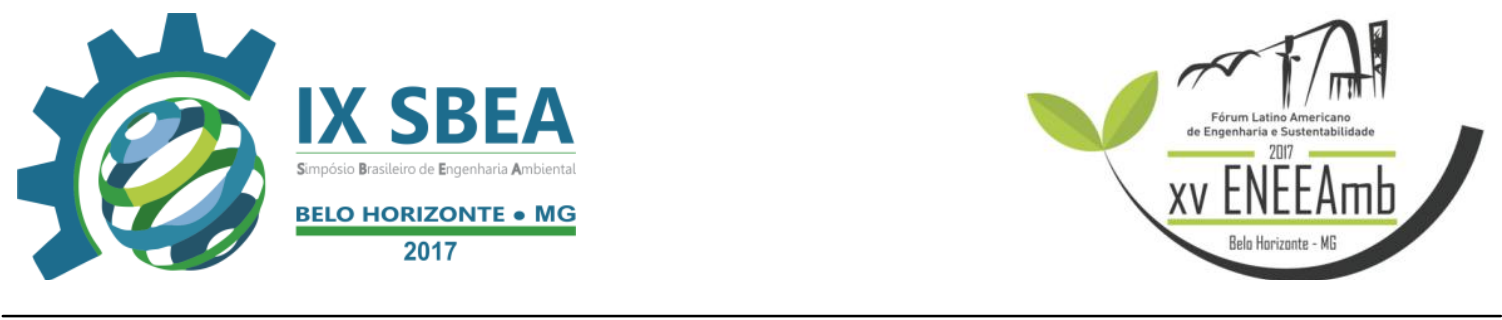

\section{RESUMO}

Com a finalidade de levantar dados e quantificar os resíduos sólidos gerados no Restaurante Universitário da UFRA, campus Belém, fazendo uma prévia separação entre orgânicos e inorgânicos, a pesquisa foi realizada em 10 dias úteis, a coleta ocorreu logo após o encerramento das atividades do mesmo, os resíduos sólidos gerados foram separados e pesados conforme o tipo, e os dados foram inseridos e organizados em tabelas e gráficos. Os resultados mostraram que 94,4\% correspondem a resíduos orgânicos, sendo os materiais plásticos ou diversos numa quantidade menor, com 3,1\% e $2,5 \%$ respectivamente. Desse modo, conclui-se que falta uma melhor gestão de resíduos sólidos, foi verificado que a maior parte desses resíduos são de origem orgânica, e que não possuem destinação correta. Há soluções viáveis para tais situações, como a compostagem, até o reaproveitamento para paisagismo. Além de uma prática responsável, seja dos gestores públicos ou dos estudantes.

Palavras-chave: Restaurante universitário, resíduos sólidos, gestão ambiental.

\section{INTRODUÇÃO/OBJETIVO}

Como se tem observado nos últimos anos, é crescente na sociedade a preocupação com o meio ambiente e com a desenfreada extração dos recursos naturais. Um dos principais problemas se dá devido ao aumento na quantidade de resíduos gerados, a má gestão e o descarte inadequado dos mesmos. O crescimento da população,

o desenvolvimento industrial e a urbanização acelerada, junto com a postura individualista da sociedade, vêm contribuindo para o aumento no uso dos recursos naturais e para a produção de resíduos, afirmam Mazzer \& Cavalcanti (2004).

O problema agrava-se ainda mais com a deficiência na legislação ambiental e com a falta de fiscalização por parte dos órgãos responsáveis. Segundo Schalch et al (2002), grande parte dos municípios brasileiros descarta seus resíduos sólidos de forma inadequada, sem qualquer controle, o que ocasiona consequências graves, como a poluição dos corpos hídricos, do solo, do ar, além de criar focos de transmissão de doenças.

Ideias e modelos de preservação surgem a todo o momento, na tentativa de minimizar os impactos gerados pelos diversos tipos de resíduos que degradam o meio ambiente. Porém, para que um trabalho ecologicamente correto seja bem sucedido, através da educação ambiental, é necessário se fazer uma mudança premente de atitude, 


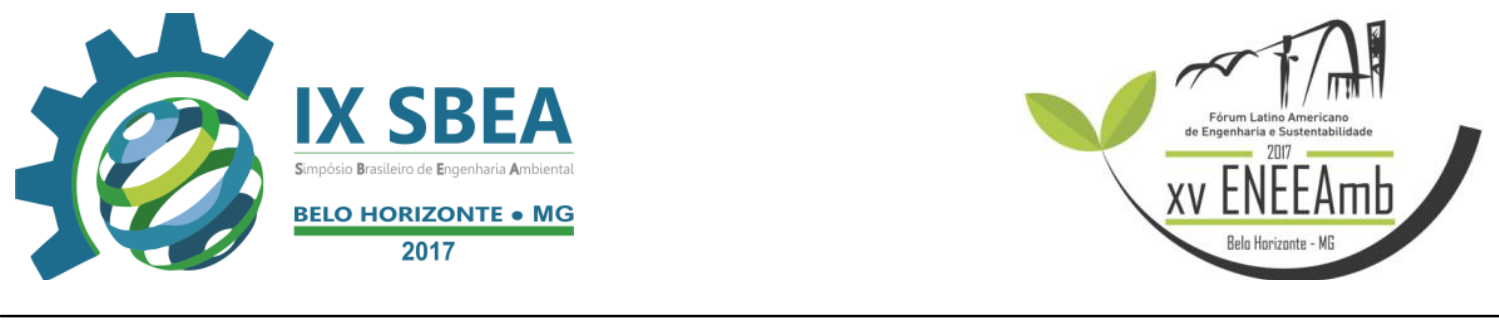

para que a ação educativa ganhe além de consciência o comprometimento com o meio ambiente. Para Bochnia et al, (2013, p.82):

\begin{abstract}
A grande preocupação com o constante acúmulo de resíduos gerados pela sociedade se traduz na busca por modelos de preservação e educação ambiental. No âmbito das Universidades brasileiras, a educação ambiental é colocada em prática através de programas de sensibilização quanto à necessidade de preservação do meio ambiente.
\end{abstract}

De acordo com Medeiros \& Ferreira (2011, p.12), no Brasil, a ampliação da coleta domiciliar e da disposição adequada dos resíduos ainda são etapas a serem vencidas. A produção de resíduos sólidos urbanos é crescente e os padrões atingidos pela reciclagem são pouco significativos no conjunto do total gerado. A legislação ambiental direcionada para resíduos de restaurantes ainda é insuficiente, o que faz com que os mesmos sejam tratados como resíduos não perigosos, sendo descartados em locais impróprios. No trecho abaixo, Margareth da Silva Corrêa e Liséte Celina Lange, (2010, p. 52, 53) confirmam a urgência de se ampliar a legislação direcionada para tais resíduos:

\begin{abstract}
Há urgência em normatizar a gestão de resíduos para o setor de refeições coletivas, não só pela dimensão e a importância desse setor na economia nacional, mas pelo potencial poluidor dos seus resíduos, que merecem criteriosa avaliação por partes dos órgãos ambientais. Possivelmente o porte, o volume de resíduos gerados e as condutas aplicadas no descarte sejam critérios suficientes para incluí-los nos empreendimentos de impacto, conforme previsto nas legislações federais, estaduais e municipais.
\end{abstract}

Nesse contexto, este artigo teve por finalidade levantar dados e quantificar os resíduos sólidos gerados no Restaurante Universitário da Universidade Federal Rural da Amazônia, campus Belém, fazendo uma previa separação entre orgânicos e inorgânicos, além de conhecer o atual procedimento de destinação final, compreendendo a problemática existente no que tange a gestão destes resíduos.

\title{
3. METODOLOGIA
}

A coleta de dados foi realizada durante 10 dias uteis, no período de 12 a 29 de abril de 2016, dentro do Restaurante Universitário (RU) da UFRA, campus Belém, que serve em média 400 refeições/dia, no horário do almoço. O público-alvo é majoritariamente formado por estudantes, que usufruem das refeições gratuitamente e 


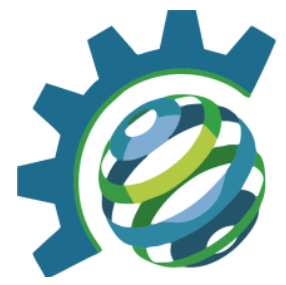

minoritariamente por funcionários da UFRA, sendo que o serviço é aberto a toda comunidade acadêmica, onde é cobrada uma taxa a quem não é estudante, pela refeição.

Os resíduos sólidos foram coletados logo após o encerramento das atividades do restaurante. A partir da utilização de luvas, máscaras e sacos plásticos, os resíduos foram separados e pesados em balanças fornecidas pelo próprio estabelecimento. No processo de pesagem foi levado em consideração o tipo de resíduo gerado, assim os resíduos orgânicos eram pesados separadamente dos resíduos plásticos e dos outros resíduos que não puderam ser separados.

Não houve separação nos setores de produção, dessa forma, foi quantificado todo e qualquer resíduo gerado no local da pesquisa. Foram coletados basicamente restos de comida, copos e garrafas plásticas. A quantidade de papel, de alumínio e outros materiais foram irrisórios, por isso qualificada como "diversos". Restos de comida que não puderam ser separados dos plásticos e papéis, também foram contabilizados desta forma.

Os dados foram inseridos em uma tabela e organizados conforme o tipo de resíduo, a saber: material orgânico, material plástico e outros. Foi obtido o acesso livre às dependências do restaurante, previamente autorizado pela nutricionista responsável, que foi devidamente notificada sobre a pesquisa através de memorando, onde os objetivos e os métodos da pesquisa foram informados e foram pedidas informações importantes sobre a destinação final dos resíduos gerados naquele local.

\section{RESULTADOS E DISCUSSÃO}

A tabela 1 mostra a quantidade de resíduos plásticos gerados no período da coleta de dados. Foi contabilizado um total de 2.972 copos descartáveis e de 39 garrafas plásticas de refrigerante. Foi observado que os copos, em sua totalidade, eram compostos de poliestireno (PS) e as garrafas de polietileno tereftalato (PET). Esta classificação de plásticos recicláveis está presente na norma ABNT NBR 13230 (1994) que estabelece a simbologia indicativa de reciclabilidade e identificação de materiais plásticos. Os seis materiais identificados pelos símbolos são os plásticos predominantes no mercado, conforme a Figura 1. 


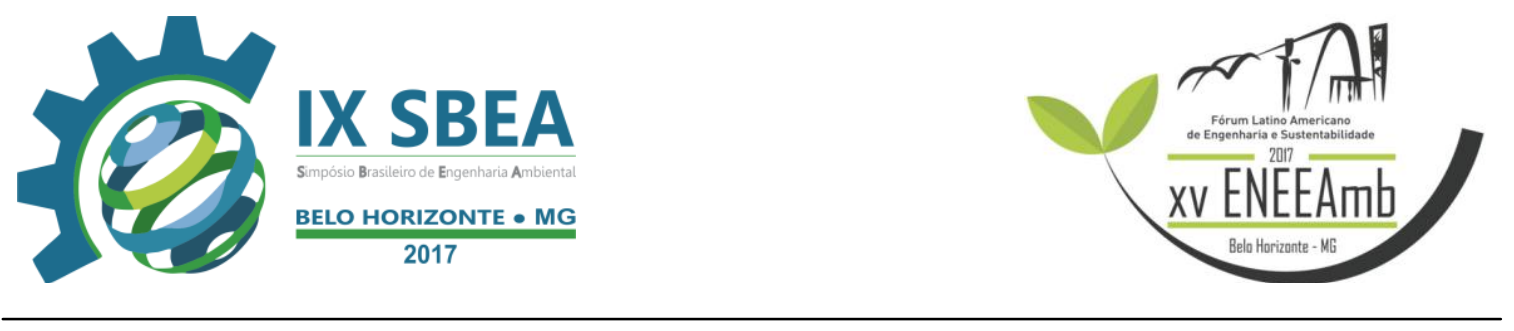

Tabela 1 - Levantamento dos resíduos plásticos gerados no período da pesquisa.

\begin{tabular}{|c|c|c|c|c|c|c|c|c|c|c|c|}
\hline \multicolumn{10}{|c|}{ PESÍDUOS PLÁSTICOS } \\
\hline \multicolumn{10}{|c|}{ CONTAGEM (Unidades) } \\
\hline $\begin{array}{c}\mathbf{1}^{\circ} \\
\text { Descrição }\end{array}$ & $\begin{array}{c}\mathbf{2}^{\circ} \\
\text { dia } \\
\text { dia }\end{array}$ & $\begin{array}{c}\mathbf{3}^{\circ} \\
\text { dia }\end{array}$ & $\begin{array}{c}\mathbf{5}^{\circ} \\
\text { dia }\end{array}$ & $\begin{array}{c}\mathbf{6}^{\circ} \\
\text { dia }\end{array}$ & $\begin{array}{c}\mathbf{7}^{\circ} \\
\text { dia }\end{array}$ & $\begin{array}{c}\mathbf{8}^{\circ} \\
\text { dia }\end{array}$ & $\begin{array}{c}\mathbf{9}^{\circ} \\
\text { dia }\end{array}$ & $\begin{array}{c}\mathbf{1 0}^{\circ} \\
\text { dia }\end{array}$ \\
\hline $\begin{array}{c}\text { Copos } \\
\text { descartáveis } \\
\text { PS (180ml) }\end{array}$ & 176 & 68 & 48 & 78 & 62 & 62 & 422 & 76 & 64 & 70 \\
\hline $\begin{array}{c}\text { Copos } \\
\text { descartáveis } \\
\text { PS (150ml) }\end{array}$ & 112 & 162 & 234 & 285 & 198 & 207 & 51 & 267 & 180 & 150 \\
\hline $\begin{array}{c}\text { Garrafas } \\
\text { plásticas } \\
\text { PET (2L) }\end{array}$ & 04 & 03 & 04 & 04 & 02 & 03 & 04 & 06 & 05 & 04 \\
\hline
\end{tabular}

Fonte: Autores.

Figura 1 - Símbolos de identificação dos materiais plásticos segundo a norma ABNT

NBR 13230.

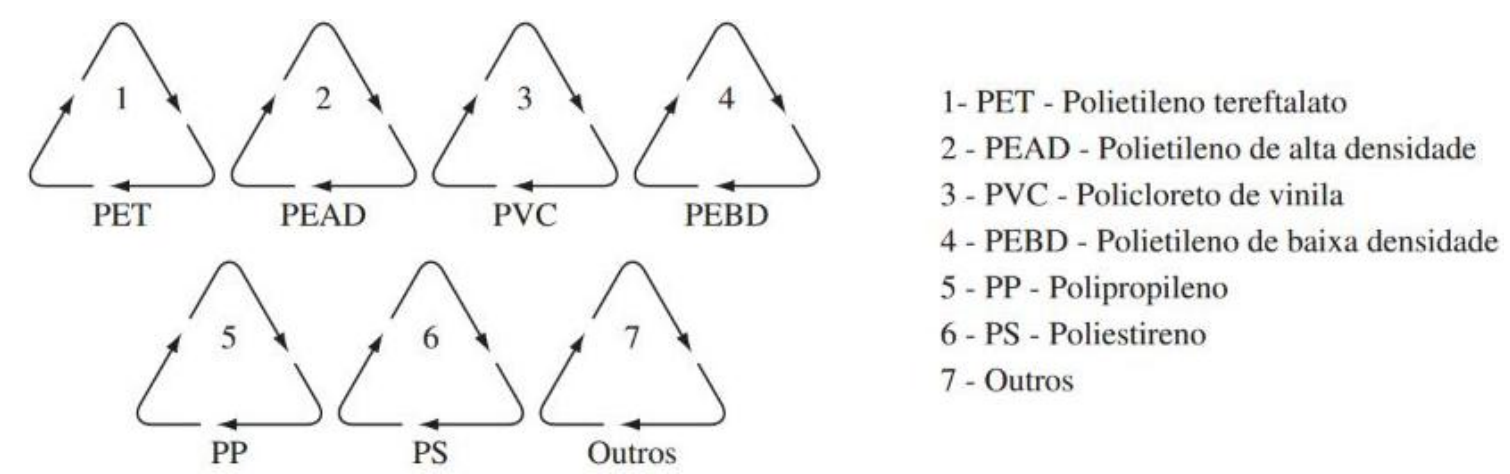

Fonte: Norma ABNT NBR 13230

Apesar dos materiais serem de fácil reciclagem, verificou-se que nada é feito com os resíduos plásticos gerados, que acabam tendo como destino final os lixões. Estes materiais poderiam perfeitamente ser utilizados em outras atividades, na sementeira do próprio campus, por exemplo, em paisagismo, ou na confecção de banco de jardins implantados no mesmo, visando uma melhor compreensão da importância da reciclagem como um dos destinos finais para tais resíduos. Isto reduziria grandemente o consumo de energia e matéria-prima para confecção de novos produtos. Outra opção 


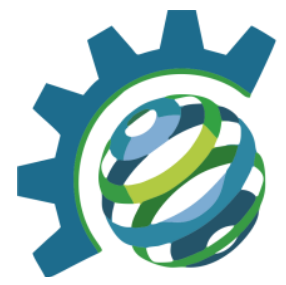

seria destinar para a coleta seletiva, que já é uma realidade em Belém. Foi observado também que os resíduos orgânicos e plásticos são misturados nas lixeiras, mesmo com avisos enormes, demonstrando a falta de preocupação com a destinação desses resíduos.

Segundo Oliveira (2012, p.24):

Devido aos benefícios econômicos limitados de muitas das técnicas de reciclagem, a utilização dos resíduos plásticos para a produção de energia ganhou destaque nos últimos vinte anos. A incineração (ou reciclagem energética, quando se utiliza a energia liberada pela combustão dos materiais) pode ser definida como a técnica de destruição térmica dos resíduos por ação de calor, produzindo idealmente dióxido de carbono e água (além de outros produtos indesejados de combustão), além de calor.

A tabela 2 mostra os tipos de resíduos sólidos gerados e suas respectivas quantidades em quilograma $(\mathrm{Kg})$. Do total de 656,92 kg de resíduos sólidos gerados, 94,4\% correspondem a resíduos orgânicos. Em média foram gerados $65,69 \mathrm{~kg}$ de resíduos nos 10 dias da pesquisa. Caso sejam servidas em torno de 400 refeições por dia, isso significa que cada pessoa produziu em média $0,164 \mathrm{~kg}$ de resíduos sólidos por dia. Se fizermos uma projeção fria, considerando o início do semestre letivo até o último dia de coleta de dados, ou seja, 83 dias úteis, o RU produziu cerca 5.452,43 $\mathrm{kg}$ de resíduos sólidos, sendo 5.145,42 kg só de resíduos orgânicos, ou seja, mais de 05 toneladas em menos de quatro meses. Nesses mesmos 83 dias foi despejado cerca de $160 \mathrm{~kg}$ de resíduos plásticos, um número considerável, uma vez que os resíduos plásticos consumidos no RU são extremamente leves.

Tabela 2 - Qualificação e quantificação dos resíduos sólidos gerados no período da pesquisa.

\begin{tabular}{|l|c|c|c|c|c|c|c|c|c|c|}
\hline \multicolumn{10}{|c|}{ PESAGEM (Kg) } \\
\hline $\begin{array}{l}\text { Material } \\
\text { orgânico }\end{array}$ & 36,500 & 33,300 & 83,500 & 101,500 & 137,800 & 99,600 & 27,400 & 35,700 & 30,500 & 34,200 \\
\hline $\begin{array}{l}\text { Material } \\
\text { plástico }\end{array}$ & 1,470 & 2,120 & 2,300 & 0,780 & 0,750 & 4,381 & 2,240 & 2,380 & 2,050 & 1,700 \\
\hline Diversos & 3,150 & 1,780 & 0,750 & 0,920 & 1,450 & 1,800 & 0,750 & 3,150 & 1,200 & 1,800 \\
\hline
\end{tabular}

Fonte: Autores. 


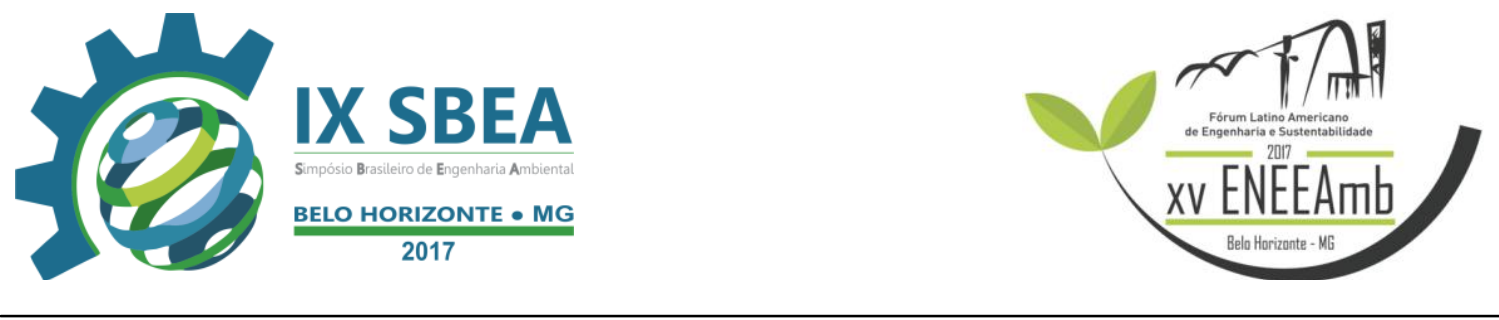

Em uma análise gráfica dos dados coletados no período da pesquisa na Figura 2, pode-se perceber claramente, a enorme quantidade de resíduos sólidos orgânicos gerados em um período de 10 dias úteis.

Figura 2 - Análise gravimétrica em peso dos resíduos coletados.

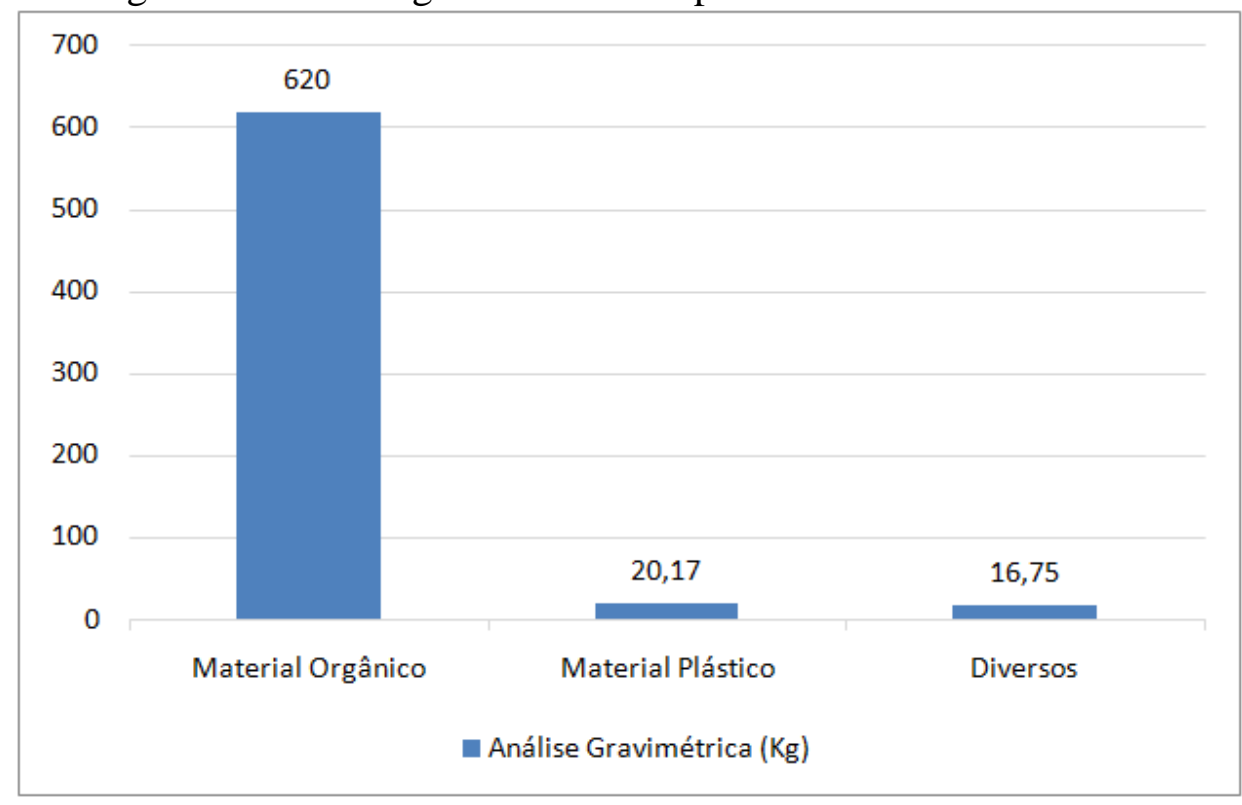

Fonte: Autores.

A Figura 3 apresenta análise percentual dos resíduos coletados, observa-se que em maior porcentagem está o material orgânico com 94,4\% desses resíduos.

Figura 3 - Análise gravimétrica percentual dos resíduos coletados.

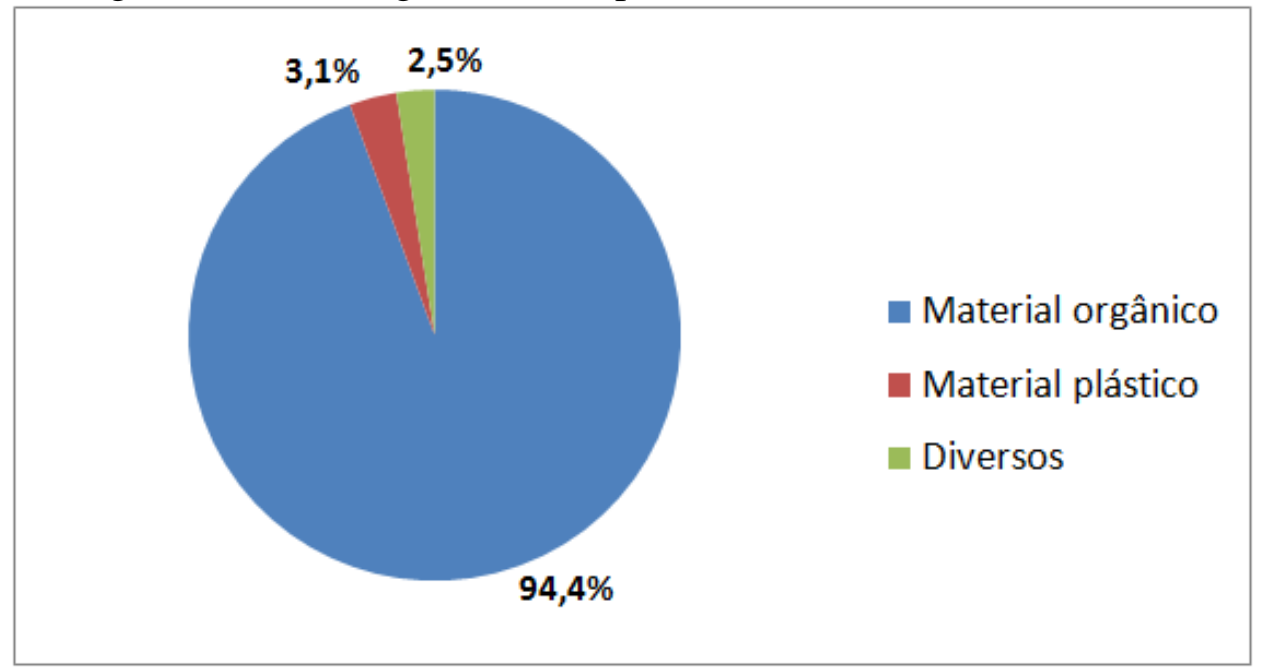

Fonte: Autores. 
Uma das propostas sugeridas para tentar solucionar essa questão, seria a separação simples dos resíduos em orgânicos e não orgânicos e posteriormente o processo de compostagem. É certo que a quantidade de resíduos gerados no R.U. não é suficiente para a implantação de uma usina de triagem e compostagem, porém, observase um volume bastante considerável, o qual poderia ser utilizado para o processo dessa técnica a partir de técnicas simples, tendo em vista que o produto final serviria para suprir as próprias necessidades da universidade, sendo utilizados na plantação de hortaliças e na atividade paisagística, e ainda daria uma destinação adequada à parte orgânica dos resíduos ali gerados.

Verificou-se que, assim como os plásticos, os resíduos orgânicos são absolutamente descartados nas lixeiras e posteriormente recolhidos e despejados como rejeitos no "aterro" do município. Contribuindo desta maneira, para a contaminação dos solos, corpos hídricos e do ar, caso não haja o manejo adequado dos mesmos, pois, haverá grande produção de chorume proveniente da matéria orgânica e liberação de poluentes químicos, derivados da decomposição de materiais não orgânicos.

Ressalta-se ainda, que não foi considerada a matéria orgânica produzida em outras atividades da universidade, tais como resíduos provenientes de capinação, poda entre outros, o que aumentaria o potencial da compostagem da universidade.

\section{CONCLUSÕES/RECOMENDAÇÕES}

Diante do exposto, conclui-se que falta uma melhor gestão de resíduos sólidos, além de constatar que não há nenhum projeto por parte dos alunos para uma gestão eficiente desses resíduos. Foi verificado que a maior parte desses resíduos são de origem orgânica, e que não possuem destinação correta, sendo descartados nas lixeiras e posteriormente recolhidos e despejados como rejeitos no "aterro" do município. Apesar dos resíduos plásticos ou diversos terem obtido uma porcentagem bem menor que a dos resíduos orgânicos, continua sendo uma quantidade significativa, pois acaba obtendo a mesma destinação que os materias orgânicos.

Porém, há soluções viáveis para tais situações, como a compostagem desses materiais orgânicos, reciclagem dos materiais plásticos, até o reaproveitamento para 


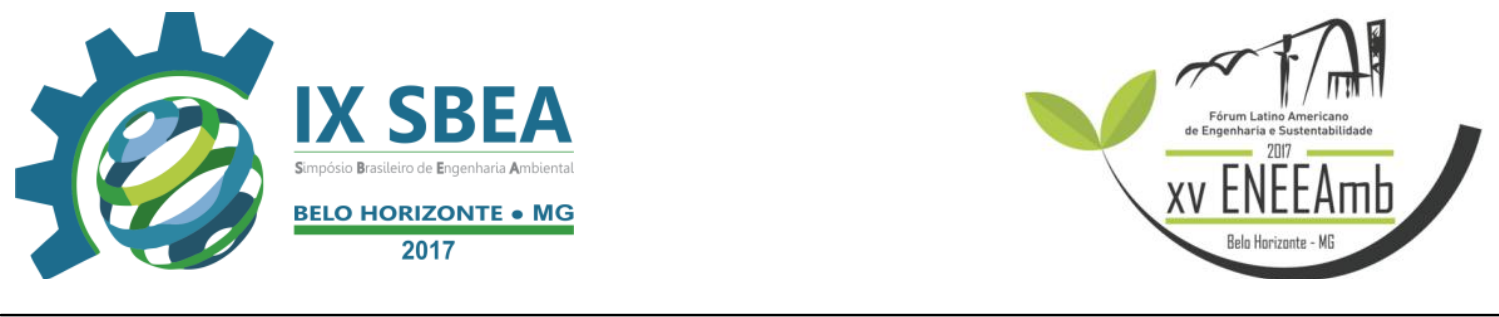

paisagismo, sendo só alguns exemplos do que pode ser feito. Além de uma prática responsável, seja dos gestores públicos ou da população.

\section{REFERÊNCIAS BIBLIOGRÁFICAS}

ANDRADE, R. M.; FERREIRA, J. A. A gestão de resíduos sólidos urbanos no Brasil frente às questões da globalização. REDE - Revista Eletrônica do PRODEMA, América do Norte, $631 \quad 03$ 2011. Disponível em <www. revistarede.ufc.br/revista/index.php/rede/article/ view/118> Acesso em 03/2016.

ASSOCIAÇÃO BRASILEIRA DE NORMAS TÉCNICAS. [Norma ABNT NBR 13230]. Rio de Janeiro, [1994]. Disponível em <www.abnt.org.br〉. Acesso em maio/16.

BILCK, A. P., SILVA, D. L. D., COSTA, G. A. N., BENASSI, V. T., GARCIA, S. Aproveitamento de subprodutos: Restaurantes de Londrina. Revista em Agronegócios e Meio Ambiente, v.2, n.1, p. 87-104, 2009. Disponível em < https://www.infoteca.cnptia.embrapa.br/bitstream/doc/1001334/1/Aproveitamentodesub produtosrestaurantesdeLondrina.pdf $>$ Acesso em 03/2016.

BoChniA, J., SANTOS, J. T., SILVA, A. G., SILVA, C. A. A gestão de resíduos sólidos gerados no restaurante universitário de uma Instituição de Ensino Superior. Engenharia Ambiental - Espírito Santo do Pinhal, v. 10, n. 2, p. 081-089, mar/abr 2013. Disponível em $<$ http://ferramentas.unipinhal.edu.br/engenhariaambiental/include/getdoc.php?id=2538 $\&$ article $=795 \&$ mode $=$ pdf $>$. Acesso em 03/2016.

CORRÊA, M. S., LANGE, L. C. Gestão de resíduos sólidos no setor de refeição coletiva. Revista Pretexto, v.12, n.1, p. 29-54, 2011. Disponível em < http://www.fumec.br/revistas/ pretexto/article/view/659/566> Acesso em 03/2016.

FERREIRA, A. G., BORBA, S. N. S. e WIZNIEWSKY, J. G. A prática da compostagem para a adubação orgânica pelos agricultores familiares de Santa Rosa/RS. Revista eletrônica do Curso de Direito - UFSM - ISSN 1981-3694. Disponível em <periódicos.ufsm.br>. Acesso em Mai/2016.

LOPES, M. L.; FONSECA, V. V. Estudo do manejo dos resíduos de um restaurante institucional da região Sul Fluminense. Interbio, v. 7, n. 1, p. 47-53, 2013. Disponível em < www.unigran.br/interbio/paginas/ed_anteriores/vol7.../ artigo5.pdf $>$. Acesso em 26/03/16.

MAZZERA, C.; CAVALCANTI, O. A. Introdução à gestão ambiental de resíduos. Infarma, Brasília, v. 16, n. 11-12, 2004. Disponível em: <http://webresol.org/textos/i04-aintroducao.pdf>. Acesso em: 23 mar. 2016. 


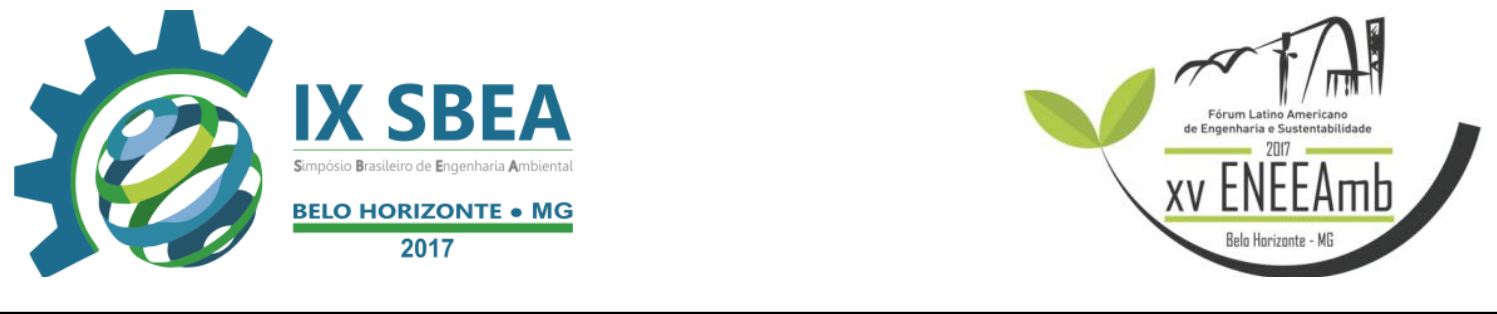

OLIVEIRA, M. C. B. R. Gestão de resíduos plásticos pós-consumo: Perspectivas para a reciclagem no Brasil. Março/2012. Rio de Janeiro/RJ. Disponível em <www.ppe.ufrj.br>. Acesso em maio/16.

SCHALCH, V. et al. Gestão e gerenciamento de resíduos sólidos. São Carlos, 2002. Disponível em: < http://www.falcoit.com.br/blog/images/easyblog_images /500/GESTAO-DE-RESIDUOS-SOLIDOS-2002.pdf> Acesso em: 23 mar. 2016. 